\title{
MOVIMENTOS SOCIAIS COMO INSTRUMENTOS DE TUTELA DE DIREITOS HUMANOS NA AMÉRICA LATINA
}

\author{
SOCIAL MOVEMENTS AS INSTRUMENTS FOR THE PROTECTION OF HUMAN RIGHTS IN \\ LATIN-AMERICA
}

\begin{abstract}
Angela Jank Calixto
Doutoranda em Direito do Estado pela Universidade de São Paulo (USP). Mestre em Direitos Humanos pela Universidade Federal de Mato Grosso do Sul (2017). Especialista em Direito Público (2016). Membro da Federação Nacional dos Pós-graduandos em Direito (2017-2021).

E-mail: angelajcalixto@gmail.com
\end{abstract}

\section{Luciani Coimbra de Carvalho}

Doutora e Mestre em Direito pela PUC/SP. Professora Adjunta da UFMS. Professora da graduação e pós-graduação stricto sensu em Direito da UFMS. Editora da Revista Direito UFMS. Desenvolve pesquisa na área de Direitos Humanos, Direitos Fundamentais, Desenvolvimento Sustentável e Direito Administrativo.

E-mail: lucianicoimbra@hotmail.com

Recebido em: 27/02/2020

Aprovado em: 12/01/2021

RESUMO: A tutela de direitos e necessidades básicas dos cidadãos latino-americanos decorre de constantes reivindicações sociais destinadas a tornar efetivos os direitos protegidos no Sistema Interamericano de Proteção de Direitos Humanos. Diante da relevância da compreensão do importante papel que a sociedade civil possui no processo de adequação das práticas e políticas internas às normas regionais de proteção humana, procura-se, por meio da adoção do método dedutivo e da condução de uma pesquisa qualitativa, exploratória e bibliográfica, evidenciar como os movimentos sociais contribuem para a busca pela melhoria das condições de vida dos cidadãos da região. Por meio da constatação de que as mobilizações sociais, ante sua aptidão de pressionar governos, possibilitam a progressiva construção de espaços públicos destinados a garantir o exercício da cidadania, conclui-se que tais mobilizações, sejam elas de cunho identitário, material, cultural ou simbólico, são de essencial importância para transformações políticas, sociais e culturais no cenário latino-americano, sobretudo no que se refere à tutela de direitos humanos.

Palavras-chave: Movimentos sociais. Direitos humanos. Sistema Interamericano de Proteção de Direitos Humanos. América Latina.

ABSTRACT: The protection of basic rights and needs of Latin American citizens is the result of constant social demands aimed at making the rights protected in the Inter-American System for the Protection of Human Rights effective. In view of the relevance of understanding the important role that civil society has in the process of adapting internal practices and policies to regional human protection standards, it is sought, through the adoption of the deductive method and the conduction of a qualitative, exploratory and bibliographic research, to show how social movements contribute 
to the improvement of the living conditions of the citizens of the region. Through the observation that social mobilizations, given their ability to pressure governments, enable the progressive construction of public spaces designed to guarantee the exercise of citizenship, it is concluded that such mobilizations, whether they are of an identity, material, cultural or symbolic nature, are of essential importance for political, social and cultural changes in the Latin American scenario, especially with regard to the protection of human rights.

Keywords: Social movements. Human rights. Inter-American System for the Protection of Human Rights. Latin America.

SUMÁRIO: Introdução; 1. Definição e teorias dos movimentos sociais: a relevância dos atores domésticos na garantia de direitos humanos; 2. Novos movimentos sociais e América Latina: a sociedade civil seu papel na exigibilidade de conformação das práticas internas às normas interamericanas; Conclusão; Referências.

\section{INTRODUÇÃO}

A Sistemática Interamericana de proteção de direitos humanos preceitua a imprescindibilidade de os países que fazem parte do sistema empreenderem todas as medidas necessárias para a adequação do ordenamento jurídico e dos atos das autoridades domésticas com as normas, recomendações e jurisprudência interamericanas. Essa obrigatoriedade decorre da própria Convenção Americana de Direitos Humanos ${ }^{1}$, bem como de uma longa construção doutrinária e jurisprudencial, pelas quais se enfatiza a responsabilidade dos membros do Executivo, Legislativo e Judiciário de cada país no processo de adequação das disposições e dos atos internos às normas e diretrizes do $\mathrm{SIDH}^{2}$.

Não obstante tal entendimento, denota-se que o processo de adequação interna à sistemática regional de proteção de direitos humanos não necessariamente decorre apenas da atuação de órgãos e autoridades estatais, mas sim deriva, partindo das ideias de Beth Simmons (2009), da atuação dos atores sociais domésticos, os quais, por meio de uma pressão bottom-up, exigem a conformidade estatal à sistemática global e regional de tutela de direitos humanos. Isso porque a sociedade civil, mediante uma atuação de forma organizada, é a principal responsável pela fiscalização e formulação de demandas destinadas a exigir das autoridades estatais que estas ajam de acordo com os compromissos por elas assumidos na esfera internacional, bem como possui um importante papel na reivindicação constante da construção de normas e do empreendimento de ações que estejam em conformidade com seus interesses de proteção de necessidades por ela consideradas imperantes (liberdade, igualdade, garantias mínimas de dignidade e de sobrevivência, entre outras).

Considerando ser a sociedade civil doméstica de cada Estado geralmente desorganizada e bastante heterogênea, entretanto, surgem dúvidas acerca de como que tal sociedade pode

\footnotetext{
${ }^{1}$ Tal exigência deriva em especial do art. $2^{\circ}$ da CADH, o qual estabelece que "Se o exercício dos direitos e liberdades mencionados no artigo 1 ainda não estiver garantido por disposições legislativas ou de outra natureza, os Estados Partes comprometem-se a adotar, de acordo com as suas normas constitucionais e com as disposições desta Convenção, as medidas legislativas ou de outra natureza que forem necessárias para tornar efetivos tais direitos e liberdades. In: ORGANIZAÇÃO DOS ESTADOS AMERICANOS. Convenção Americana de Direitos Humanos. 22 de novembro de 1969. Disponível em: <https://www.cidh.oas.org/basicos/portugues/c.convencao_americana.htm>. Acesso em: 26 jan. 2020.

${ }_{2}^{2}$ Para uma melhor compreensão de referida responsabilidade e construção doutrinária e jurisprudencial, vide: CARVALHO, Luciani Coimbra de; CALIXTO, Angela Jank. Diálogos interjudiciais: a obrigatoriedade de seu desenvolvimento no Sistema Interamericano de Proteção dos Direitos Humanos. Revista eletrônica do curso de direito da UFSM, v. 14, 2019. Disponível em: 〈https://periodicos.ufsm.br/revistadireito/article/view/30919>. Acesso em $18 / 02 / 2020$.
} 
concretamente exercer tal papel. Referida indagação deriva inclusive do fato de que, em que pesem os Estados latino-americanos serem formalmente reconhecidos como democracias, muitas vezes não há grande participação dos cidadãos latino-americanos na condução das políticas estatais, não possuindo as sociedades civis poder suficiente para constranger seus governantes a observarem em toda e qualquer prática as convenções internacionais de direitos humanos por eles ratificadas.

Diante da dúvida levantada, denota-se a defesa de que um dos principais modos de as sociedades lograrem êxito na consecução de medidas para a garantia da conformidade das normas e práticas estatais com as normas interamericanas é a partir da constante mobilização social de atores domésticos (SIMMONS, 2009) que se encontram preocupados com a forma em que a política governamental é conduzida no país em que vivem e com a garantia de que suas necessidades básicas (materiais ou simbólicas) sejam devidamente atendidas, sem que as elites estatais abusem da prerrogativa a elas conferida pelo povo latino-americano na gestão do aparato estatal. Isso porque os movimentos sociais possuem a aptidão de pressionar governos e, ainda, progressivamente levar à construção de espaços públicos destinados a garantir o legítimo exercício da cidadania, por meio de constantes reivindicações culturais e políticas pelos cidadãos, aspecto esse significativo para a constante observância dos interesses e direitos básicos da população.

As distintas características das mobilizações sociais, tidas como mecanismos essenciais postos à disposição da sociedade para que esta reivindique transformações, e os fatores que influenciam a tomada de decisões para que os atores sociais mobilizem-se para a demanda de direitos e garantias básicas devem, portanto, ser objeto de estudo mais aprofundado, diante de sua significância para a conformidade das práticas internas com a sistemática regional de proteção de direitos humanos e para o exercício de uma cidadania ativa destinada à preservação e consolidação da democracia na região.

Tendo em vista o exposto, pretende-se no presente trabalho demonstrar a correlação entre direitos humanos, movimentos sociais e conformação interna às normas e diretrizes interamericanas, partindo de uma perspectiva bottom-up, consoante já mencionado. Tem-se como objetivo evidenciar como que no âmbito da América Latina a participação ativa da sociedade civil por meio de movimentos sociais é imperante para a contínua tutela de direitos humanos, ante a aptidão que as mobilizações sociais possuem de gerar transformações políticas e sociais no cenário latino-americano.

Para tanto, primeiramente são tecidas considerações acerca dos distintos conceitos, teorias e fatores associados aos movimentos sociais, com o fim de apresentar um panorama geral acerca de tais movimentos e identificar esses como relevantes para mudanças sociais, sobretudo no que diz respeito à concretização de direitos humanos. Após, demonstra-se como que historicamente os movimentos sociais desenvolveram-se na América Latina a partir da influência de normas internacionais de direitos humanos (entre outros aspectos) e qual o sentido de tais mobilizações para o processo de adequação das normas e práticas domésticas, para a proteção de direitos humanos e para a exigência de democratização do espaço latino-americano.

No tocante ao procedimento metodológico, adota-se o método dedutivo para a resolução do objetivo proposto, já que parte de constatações gerais para chegar a conclusões particulares, bem como se promove uma pesquisa de cunho qualitativo que, no tocante aos seus objetivos, possui eminente cunho exploratório e, no tocante aos seus meios, caracteriza-se por ser uma pesquisa de caráter bibliográfica.

\section{DEFINIÇÃO E TEORIAS DOS MOVIMENTOS SOCIAIS: A RELEVÂNCIA DOS ATORES DOMÉSTICOS NA GARANTIA DE DIREITOS HUMANOS}

Para a compreensão do modo que os movimentos sociais levam à conformação das práticas e normas internas aos tratados de direitos humanos na América Latina, há de se efetuar uma revisão das principais teorias relativas a tais movimentos e de suas contribuições para a 
identificação das lutas sociais como atos que positivamente impactam a política doméstica, em contraposição à ideia de que os movimentos referem-se a anomias sociais que devem ser evitados. Assim, visa-se nessa sessão enfatizar as contribuições das distintas teorias de movimentos sociais para a compreensão da importância da mobilização social em favor da garantia de direitos e da construção de espaços para reivindicações culturais e políticas pelos cidadãos.

Desta feita, convém retomar, mesmo que sucintamente, algumas das teorias contemporâneas dos movimentos sociais desenvolvidas no âmbito da sociologia, para que se possa vislumbrar os pontos em comum e as rupturas que emergem entre as distintas concepções e para que se possa compreender a emergência de movimentos sociais na América Latina a partir, sobretudo, da década de 1960, aspecto a ser tratado no próximo tópico.

Nesse tocante, frisa-se que as teorias sobre movimentos sociais têm sido objeto de análise pela sociologia desde o século XIX, os estudos acerca das ações sociais coletivas sendo originalmente desenvolvidos por meio das ideias de Durkheim acerca da anomia e da solidariedade social e posteriormente sendo complementadas pela crítica social de Marx acerca dos conflitos entre capital e trabalho e sobre a resistência dos operários à opressão e desigualdade social e pelos estudos de Max Weber sobre ação social e sua institucionalização no mercado e no Estado (VIEIRA, 2013).

Nas teorias clássicas, os movimentos sociais, vistos como frutos de tensões sociais (anomias sociais), eram decorrentes de respostas cegas e irracionais de indivíduos desorientados pelo processo de mudança pelo qual passava a sociedade industrial, destinados à quebra da ordem social vigente (GOHN, 1997). ${ }^{3}$ Os movimentos eram vistos como revolucionários, de mobilização de massas, que visavam apossar-se do poder do Estado e, consequentemente, substituir a forma opressora de poder estatal, detendo eles função instrumental, já que destinados à distribuição radical de bens econômicos por processos próprios que incluíam o uso da coerção e da violência (ALEXANDER, 1998).

Denota-se, portanto, que em tais movimentos as considerações de caráter ético, moral e cultural não eram consideradas, dando-se ênfase à necessidade de distribuição de riquezas para a transformação social. O conflito resultaria do choque de interesses entre o Estado, detentor do poder, e a sociedade oprimida, sendo destinado a mudanças estruturais na sociedade (ALEXANDER, 1998).

Movimentos assim caracterizados, entretanto, perderam sua centralidade na década de 1960. Isso se deve, para Della Porta e Diani (2006), a uma série de mudanças estruturais significativas, quais sejam: a substituição do modelo fordista de produção para um sistema caracterizado pelo uso de tecnologia, pela diversificação dos meios de produção e pela formação de pequenos grupos de trabalho; a descentralização da produção, com o consequente crescimento da economia informal; a expansão da atividade econômica para outras regiões ou países; o declínio da importância da atividade industrial, em favor de serviços administrativos, entre outros. Tais processos enfraqueceram as condições estruturais que até então facilitavam a emergência de demandas coletivas de classe, tornando mais difícil aos atores se organizarem com o fim de buscar propósitos comuns.

Há nessa época uma mudança de cenário, ressurgindo uma variedade de movimentos sociais nos EUA e na Europa, movimentos esses que não mais tinham como objetivo uma revolução política destinada à tomada do poder do Estado e não mais se baseavam em distinções de classe, mas sobretudo em injustiças sociais decorrentes de etnia (movimento por direitos civis

\footnotetext{
${ }^{3}$ Gohn (1997) pontua a existência de uma variedade de correntes clássicas que serviram de base para a teoria dos movimentos sociais, listando a Escola de Chicago (de Herbert Blumer), a teoria sobre a sociedade de massas (de Fromm, Hoffer e Kornhauser), a abordagem sociopolítica (de Lipset e Rudolf Heberle), a teoria do comportamento coletivo sob a ótica do funcionalismo (de Parsons, Turner, Killian e Smelser), e as teorias organizacionaiscomportamentalistas (de Selzinick, Gusfield e Messinger). Contudo, tendo em vista o foco dessa tese, não serão analisadas as teorias em questão, listando apenas as características comuns às teorias clássicas dos movimentos sociais. 
nos EUA), gênero (feminismo), estilo do vida (ambientalismo), orientação sexual (movimento LGBT) entre outros (ALONSO, 2009), injustiças essas eminentemente atreladas a reivindicações de direitos humanos.

Tratavam-se, para Angela Alonso (2009), de movimentos sociais, por serem ações coordenadas ocorrendo fora das instituições políticas, os quais deixaram, entretanto, de ser protagonizadas por proletários, como até então vinha ocorrendo. Passaram a ser protagonizadas por grupos sociais marginalizados, excluídos da sociedade política, ou insatisfeitos com as injustiças sociais, como mulheres, estudantes ou profissionais liberais, que reivindicavam não a alteração das condições de vida, mas sim a melhora da qualidade de vida e a afirmação da diversidade de modos de vivê-la. Referem-se a demandas pós-materiais (INGLEHART, 1971), relacionadas à busca por mudanças na sociabilidade e na cultura (ALONSO, 2009) ${ }^{4}$ e, em sua essência, associadas a lutas por direitos humanos básicos.

As principais inovações desses novos movimentos sociais são, para Della Porta e Diani (2006), a presença de uma ideologia crítica com relação ao progresso e ao modernismo, a formação de estruturas organizacionais descentralizadas e participativas, a defesa da solidariedade interpessoal contra burocracias e a demanda por espaços autônomos ao invés de vantagens materiais.

Em virtude da insurgência desses novos movimentos, surgiram distintas teorias para caracterizar esses movimentos surgidos a partir da década de 1960, a doutrina enumerando três teorias em especial, quais sejam, a Teoria da Mobilização dos Recursos - TMR (cujos principais expoentes são McCarthy e Zald), a Teoria do Processo Político - TPP (preconizada por Charles Tilly, Sidney Tarrow e Doug McAdam) e a Teoria dos Novos Movimentos Sociais - TNMS (elaborada essencialmente por Alain Touraine, Jürgen Habermas e Alberto Melucci) ${ }^{5}$. Tais teorias possuem características próprias, considerando-se necessário discorrer acerca delas, para fixar o que deve ser compreendido como movimento social para os fins desse trabalho e em que sentido há estrita correlação entre tais movimentos e a luta por direitos humanos.

As primeiras duas teorias surgem em contraposição à ideia clássica de que os movimentos sociais se desenvolvem de maneira irracional e caótica e ante a existência de insatisfações individuais não canalizadas pelas instituições. Tais teorias, por meio da defesa a racionalidade dos movimentos sociais, salientam que descontentamentos e motivos para a mobilização sempre existiram, sendo que mais importante do que averiguar as razões da mobilização era explicar o processo da mobilização, por meio de uma faceta racional e estratégica da ação coletiva (ALONSO, 2009).

Com relação à teoria da mobilização de recursos, sustenta Alonso (2009) que de acordo com os ensinamentos de McCarthy e Zald (1977), principais expoentes de tal corrente de pensamento, a decisão de agir seria um ato deliberativo individual, resultado do cálculo racional entre benefícios e custos. Desse modo, a mobilização social apenas ocorreria na presença de recursos materiais (financeiros e infraestrutura) e humanos (atores sociais) e em havendo uma

\footnotetext{
${ }^{4}$ No tocante ao aspecto cultural dessas demandas sociais, Della Porta e Diani (2006) apontam que as mudanças na estrutura social e na ordem normativa necessariamente decorrem de um processo de evolução cultural, por meio do qual novas ideias emergem na mente dos indivíduos. Diante de tal fato, os autores apontam que quando as normas tradicionais não mais refletem comportamentos considerados adequados, a insatisfação é generalizada e as instituições não respondem adequadamente, os indivíduos se vêem forçados a desafiar a ordem social por meio de distintas formas de não conformidade, desenvolvendo, pois, movimentos sociais.

${ }^{5}$ As teorias expostas retratam os principais estudos doutrinários surgidos entre teóricos europeus e norte-americanos no que se refere ao estudo dos movimentos sociais. Salienta-se, entretanto, que não se ignora a riquíssima produção teórica de autores latino-americanos sobre o tema, como os trabalhos de Ilse Scherer-Warren, Paulo Krischke, Maria da Glória Gohn, Maria Célia Paoli, Eder Sader e, na área do direito, de Antônio Carlos Wolkmer. Contudo, serão apresentadas nessa parte da dissertação as teorias base dos movimentos sociais, optando-se por trazer as ideias dos teóricos latino-americanos no terceiro capítulo da tese, ante o fato de tais teorias enfatizarem a relação entre democracia e movimentos sociais, objeto de análise em referido capítulo desta tese.
}

Revista de Direito Brasileira | Florianópolis, SC | v. 27 | n. 10 | p.31-50 | Set./Dez. 2020 
capacidade de organização, as ideologias, cultura, valores e a identidade coletiva não possuindo qualquer relevância para o desenvolvimento da mobilização.

Enfatiza-se o apoio da sociedade e as constrições do fenômeno dos movimentos sociais, por meio do estudo do conjunto de recursos que incentivam ou obstaculizam os movimentos, das formas de organização que impactam as mobilizações (ante o entendimento de que qualquer movimento requer um mínimo de organização), do envolvimento e dependência do apoio externo para o sucesso e da análise de custos e benefícios para a explicação do envolvimento individual e organizacional nos movimentos (MCCARTHY; ZALD, 1977).

Na visão de McCarthy e Zald (1977, p. 1217-1218, tradução livre), movimentos sociais correspondem a "um conjunto de opiniões e crenças em uma população que representam preferências pela mudança de alguns elementos da estrutura social e/ou distribuição de

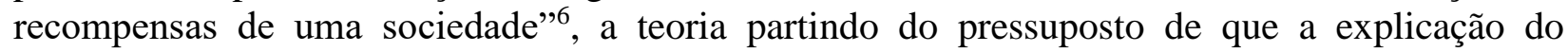
fenômeno coletivo requer atenção detalhada ao conjunto de incentivos, mecanismos de redução de custos e benefícios na carreira que levam poucos indivíduos a suportar os gastos com os movimentos sociais.

Ao contrário das concepções clássicas (que salientam que os movimentos são baseados no sentimento de injustiça social da população, a qual usa de processos de barganha, persuasão ou violência para influenciar autoridades, e que ignoram como os movimentos podem se utilizar de seu meio para atingir propósitos próprios), McCarthy e Zald (1977) defendem que os movimentos podem ou não serem baseados no senso de injustiça social da população (sendo possível que apoiadores sequer tenham qualquer comprometimento com os valores do movimento), ocorrem por meio de táticas de neutralização e transformação da massa e da elite em apoiadores e funcionam mediante a percepção de que é a sociedade que provê a infraestrutura necessária para a mobilização.

A importância da teoria em evidência cinge na sua constatação de que não é suficiente apenas identificar a existência de tensões e conflitos estruturais, sendo necessário também entender quais as condições que permitem que o descontentamento seja transformado em uma mobilização social (DELLA PORTA; DIANI, 2006).

Contudo, em que pesem os avanços que trouxe para a compreensão dos movimentos sociais, a teoria foi bastante criticada, seja ao não considerar a imprescindibilidade de formação de uma identidade coletiva para que as mobilizações fossem levadas a efeito, seja ao desvincular os movimentos das macroestruturas, dos aspectos culturais e históricos que incitam os movimentos ${ }^{7}$, seja ainda ao definir movimentos sociais de forma análoga com uma firma, motivo pelo qual teve pouca ressonância na Europa e na América Latina (ALONSO, 2009). Ainda, críticas importantes foram tecidas por McAdam, Tarrow e Tilly (2001), por defenderem que a teoria ressalta demasiadamente similaridades entre movimentos sociais e política de interesses, por Melucci (1980), o qual aduz que a teoria em evidência trata com indiferença as causas estruturais do conflito e as causas específicas que efetivamente levam os atores sociais a se mobilizarem, e por Tarrow (2011), ao ressaltar que a teoria ignora que muitos dos novos movimentos que surgiram entre 1960 e 1970 careciam de organização formal quando emergiram.

Semelhante à teoria da mobilização de recursos, Charles Tilly, Sidney Tarrow e McAdam ${ }^{8}$ desenvolveram a teoria do processo político (political process theory), a qual também defende o caráter racional das ações coletivas.

\footnotetext{
${ }^{6}$ No original: " $a$ set of opinions and beliefs in a population which represent preferences for changing some elements of the social structure and/or reward distribution of a society".

${ }^{7}$ Aponta Alonso (2009) que o enquadramento macro-histórico dos movimentos sociais apenas ocorre a partir da teoria do processo político e das teorias dos novos movimentos sociais, as quais se insurgiam contra explicações deterministas e economicistas da ação coletiva e contra a ideia de um sujeito histórico universal, defendendo a combinação da política e da cultura para a explicação dos movimentos sociais (ALONSO, 2009).

${ }^{8}$ Doug McAdam (1982) sintetizou as abordagens norte-americanas em uma modelo de processo político da mobilização social, por meio do mapeamento do desenvolvimento do movimento por direitos civis nos EUA e a relação desse movimento com mudanças políticas, organizacionais e de consciência.
}

Revista de Direito Brasileira | Florianópolis, SC | v. 27 | n. 10 | p.31-50 | Set./Dez. 2020 
Entretanto, em sentido diverso da TMR, a teoria foca não na distribuição de recursos, mas no processo político que influencia os movimentos sociais, ante a percepção de que as mobilizações são eminentemente ligadas a elementos macroestruturais, como a política e a cultura, as quais influenciam a decisão dos atores sociais de demandarem transformações. Consoante Alonso (2009, p. 55-56), "enquanto a TMR enfatiza recursos materiais disponíveis para ativistas individuais, a TPP prioriza uma estrutura de incentivos e/ou constrangimentos políticos, que delimita as possibilidades de escolha dos agentes entre cursos de ação".

Em geral, tal teoria analisa as características do sistema político que influenciam o crescimento de ações políticas não institucionalizadas e as formas em que tais ações adquirem em diferentes contextos históricos (DELLA PORTA; DIANI, 2006). Dessarte, movimentos apenas podem ser estudados em sua conexão com a política, de forma que variam em suas estratégias, estruturas e sucesso em diferentes tipos de Estado (TILLY, 1978).

Segundo o preconizado em tal teoria, os movimentos sociais seriam formas históricas de expressão de reivindicações ${ }^{9}$ (ALONSO, 2009), apenas surgindo, entretanto, quando há condições políticas favoráveis para tanto. Nesse sentido assevera Tilly (1978), principal teórico dessa corrente de pensamento, ao esclarecer que são as estruturas de oportunidades políticas (EOPs), que levam à mobilização, sendo que apenas quando há mudanças nas EOPs, ou seja, nas dimensões formais e informais do ambiente político, que se abrem ou se criam novos canais para a expressão de reivindicações para grupos sociais que se encontram fora da esfera do poder.

Desse modo, de acordo com essa visão, qualquer movimento social não se desvincula da história e da política, emergindo, para Tarrow $(2011)^{10}$, como resposta a mudanças nas oportunidades e ameaças políticas, ou seja, quando os atores políticos percebem e reagem a incentivos materiais, ideológicos, partidários, coletivos, duradouros e episódicos.

Frisa-se que nessa concepção a questão da solidariedade entre atores sociais é posta em evidência, Tarrow (2011, p. 9) asseverando serem os movimentos sociais "desafios coletivos, baseados em propósitos comuns e solidariedades sociais, em interações continuadas com elites, oponentes e autoridades", e Tilly (1978) sustentando que a coordenação de interesses necessariamente depende da solidariedade (elemento cultural), a qual, para o autor, é produto da sensação de pertencimento a uma categoria e da formação de redes interpessoais que vinculam seus membros, a mobilização correspondendo ao processo pelo qual um grupo cria solidariedade e adquire o controle coletivo sobre os recursos necessários para a ação.

Todavia, o foco principal da teoria cinge à análise do processo político, o qual influencia as estruturas existentes para a mobilização (recursos formais e informais que favorecem a organização). Em razão de tal foco, a teoria em questão também é criticada por teóricos dos novos movimentos sociais, Melucci (1980) salientando que tal perspectiva adota uma espécie de reducionismo político, ignorando que os movimentos sociais pós-modernos tem se desenvolvido em razão do contexto cultural e não político em que os atores sociais se encontram ${ }^{11}$.

Em direção diversa das teorias acima retratadas, surge no mesmo período a Teoria dos Novos Movimentos Sociais (TNMS), a qual, assim como a TPP, pontua o enquadramento macro histórico dos movimentos sociais e associa a mudança social com distintas formas de conflitos. A diferença reside no fato de as TNMS produzirem uma interpretação cultural para os movimentos

\footnotetext{
9 Tilly (2010) enfatiza que tal historicidade explica as características específicas de movimentos, identifica as mudanças significativas no funcionamento dos movimentos sociais e alerta para as mudanças políticas que tornam possíveis os movimentos sociais.

10 Tarrow, em sua obra "Power in movement: social movements and contentious politics" (2011), não trata especificamente de movimentos sociais, mas sim de modo mais abrangente de ações coletivas contenciosas, aduzindo que a política contenciosa é produzida em casos em que ameaças são vislumbradas e oportunidades são percebidas e quando a existência de aliados é demonstrada e a vulnerabilidade de oponentes é exposta.

${ }^{11}$ Da mesma forma, McCann (2006) tece críticas especificamente às ideias de Tilly, ao salientar que a teoria do teórico não distingue claramente movimentos sociais de grupos de interesses, partidos políticos minoritários, protestos populares, desobediência civil, violência terrorista e outras formas de ação coletiva.
}

Revista de Direito Brasileira | Florianópolis, SC | v. 27 | n. 10 | p.31-50 | Set./Dez. 2020 
sociais, ao invés de uma visão política, e de darem um maior enfoque a tal aspecto, sem se preocupar tanto com a explicação racional dos movimentos (ALONSO, 2009). Além disso, tais teorias conferiam maior ênfase ao potencial transformador dos movimentos sociais na tutela da dignidade humana e à oposição de tais movimentos aos aparelhos de Estado autoritários (GOIRAND, 2009).

Apesar de cada teórico tecer considerações distintas, as variadas TNMS compartilham basicamente de um mesmo argumento, qual seja, que uma mudança macroestrutural no século XX teria alterado a natureza do capitalismo, de forma a fazer com que o trabalho e a produção deixassem de ser seu centro e a fazer surgir uma nova sociedade (a sociedade pós-industrial), que demandava o foco em novos temas, relacionados a direitos humanos. Angela Alonso (2009, p. 67) resume bem o elemento comum das distintas TNMS, que sustentavam em síntese que

As reivindicações teriam se deslocado dos itens redistributivos, do mundo do trabalho, para a vida cotidiana, demandando a democratização de suas estruturas e afirmando novas identidades e valores. Estaria em curso uma politização da vida privada. Os movimentos de classe dariam lugar, assim, a novos movimentos expressivos, simbólicos, identitários, caso do feminismo, do pacifismo, do ambientalismo, do movimento estudantil. [...]

Os novos movimentos sociais seriam, então, antes grupos ou minorias que grandes coletivos. Suas demandas seriam simbólicas, girando em torno do reconhecimento de identidades ou de estilos de vida. Recorreriam à ação direta, pacífica, baseada numa organização fluída, não hierárquica, descentralizada, desburocratizada. Não se dirigiriam prioritariamente ao Estado, mas à sociedade civil, almejando mudanças culturais no longo prazo.

As sociedades pós-industriais, que nas palavras de Alexander (1998, p. 13) "constituem arranjos estruturais que criam [...] novas formas de estratificação, novos grupos de conflito, novos padrões de dominação e novas percepções dos objetivos e interesses em jogo", impõem a necessidade de reivindicações com aspecto cultural e identitário e implicam o surgimento de movimentos sociais distintos dos movimentos clássicos, que levam em consideração a subjetividade dos atores sociais e que detêm uma sensibilidade a aspectos históricos e institucionais.

Enquadradas como teorias culturalistas (Touraine e Melucci) ou teorias preocupadas com a questão da justiça social e com a necessidade de redistribuição de bens e direitos (Habermas e Nancy Fraser), elas enfatizam o processo de construção e reconstrução de identidades sociais, segundo fatores religiosos, étnicos, interesses e direitos de atores sociais, a partir do agir coletivo (GOHN, 1997).

No tocante à teoria proposta por Alain Touraine (1981, p. 29, tradução livre) ${ }^{12}$, esta esclarece que os movimentos sociais correspondem a condutas coletivas eminentemente ligadas ao tipo de sociedade, sendo definidos não mais como a rejeição marginal da ordem (como nos movimentos clássicos), mas como "as forças centrais que lutam entre si pelo controle da produção da sociedade por si mesma e a ação de classes destinadas a moldar a historicidade"13.

O critério diferenciador desses novos movimentos, para Touraine (2006), é que se vislumbra que o estudo dos movimentos sociais não pode ser separado da noção de que a sociedade constitui-se como um sistema em que forças sociais competem entre si pelo controle do campo cultural. Isso porque nesses movimentos pós-modernos os atores centrais do conflito não são mais

\footnotetext{
${ }^{12}$ Frisa-se que Touraine sugere a substituição da terminologia "movimentos sociais" para "movimentos culturais" (ainda que entenda que não há erro na utilização da primeira expressão), ante o deslocamento dos conflitos para a ordem simbólica, já que não mais se reivindicam tão somente transformações sociais, mas sim transformações morais.

${ }^{13}$ No original: "the central forces fighting one against the other to control the production of society by itself and the action of classes for the shaping of historicity".
} 
classes ligadas à produção industrial, mas sim grupos com visões opostas quanto ao uso e à alocação de recursos cognitivos e simbólicos ${ }^{14}$.

Como esclarece Polletta e Jasper (2001), nessa época, os atores sociais deixam de buscar transformações derivadas tão somente da distinção entre classes sociais, ou seja, deixam de buscar tão somente a redistribuição do poder político, para buscar transformações normativas e culturais destinadas ao reconhecimento de novas identidades e modos de vida e de aspectos centrais relacionados à concretização da dignidade humana. Do mesmo modo, os atores sociais deixam de ser as diferentes classes sociais, passando a ser os grupos marginais em relação aos padrões de normalidade sociocultural (minorias excluídas do processo político tradicional, como negros, indígenas, homossexuais, mulheres, entre outros), que se organizam não para combater o Estado ou conquistar o poder, mas para persuadir a sociedade a mudar algumas orientações valorativas (ALONSO, 2009).

Há, então, uma modificação das reivindicações para a busca da realocação de recursos simbólicos, motivo pelo qual Touraine (2006) esclarece ser a formação da identidade coletiva ${ }^{15}$ de essencial importância para caracterizar um movimento social, esta se referindo ao senso de propósito comum e comprometimento compartilhado com uma causa, o qual possibilita que ativistas e organizações vislumbrem-se como interconectados.

Por outro lado, Habermas (1981), em sua TNMS, sustenta ser a "colonização do mundo da vida" que criaria meios para as novas mobilizações sociais e para a luta simbólica em torno de definições da boa vida. Os novos movimentos seriam, dessarte, uma forma de resistência a tal colonização, à padronização, à racionalização das interações sociais, demandando qualidade de vida, equidade, possibilidade de participação, defesa de direitos humanos, etc. ${ }^{16}$

Noutro norte, na concepção apresentada por Melucci, esta se diferencia das anteriores sobretudo em razão de aproximar a TNMS com a TMR e a TPP, já que o autor, em consonância com tais teorias, também defende que os movimentos surgem a partir de um campo de oportunidades e constrangimentos (com um cálculo de custos/benefícios), e que a existência de relações ou organizações prévias facilitam o engajamento (ALONSO, 2009).

Contudo, ao contrário de tais perspectivas, parte-se da visão de que parte substancial dos movimentos consistiria no processo de construção de uma identidade coletiva ${ }^{17}$, de modo que a racionalidade de um movimento social não seria produto apenas da oportunidade e de cálculos, mas também de um reconhecimento emocional (relacionado à identidade coletiva) dos atores quanto à necessidade de transformação social. Nessa teoria os movimentos seriam, dessa maneira, simultaneamente racionais e emocionais (ALONSO, 2009).

Melucci (1980) ressalta que o controle nas sociedades pós-industriais passa a ser não mais apenas sobre a produção, mas também sobre as relações sociais, serviços e o consumo, os mecanismos de controle não mais cingindo tão somente sobre a força laboral, mas sobretudo sobre a manipulação da informação, sobre o processo de formação de símbolos e sobre a intervenção nas

\footnotetext{
14 Touraine (2006) enfatiza que há dois tipos de sociedades: a sociedade industrial e a pós-industrial (sociedade programada). Na primeira, com fulcro na indústria, no trabalho industrial e no modelo fordista de produção, os conflitos produtivos predominavam, sendo os trabalhadores industriais os atores das mobilizações. Já na segunda, na qual a indústria e o trabalho perdem centralidade e a dominação se torna eminentemente cultural, os conflitos deixam de concentra-se ao plano econômico, para avançar para questões da vida privada, ganhando dimensões simbólicas.

15 Polleta e Jasper (2001) salientam ser a identidade coletiva a resposta às lacunas dominantes das teorias da mobilização de recursos e do processo político, as quais focam em como o processo de mobilização ocorre, sem tecer grandes considerações acerca dos motivos que levam à mobilização.

${ }^{16}$ Segundo Habermas (1981), os novos movimentos seriam uma forma de defesa e reação a algumas situaçõesproblema, estes decorrentes do aumento da complexidade da sociedade contemporânea. Desvinculada da demanda por bens, seriam tais movimentos associados à afirmação de identidades e à preservação da autonomia das distintas formas de vida ameaçadas pela racionalização sistêmica engendrada pelo Estado e pelo mercado.

${ }^{17}$ Apesar de Habermas e Touraine terem associado movimentos sociais com a construção de identidades coletivas, foi Melucci que se dedicou à produção de uma teoria com foco primordial em tal aspecto como de essencial importância para os movimentos sociais.
}

Revista de Direito Brasileira | Florianópolis, SC | v. 27 | n. 10 | p.31-50 | Set./Dez. 2020 
relações interpessoais. Nessas novas sociedades, o controle é exercido sobre a identidade interpessoal e sobre a própria estrutura do indivíduo (ou seja, sobre sua personalidade, consciência e identidade biológica).

Ante tal controle, são as identidades pessoal e social dos indivíduos que são percebidas como produto das ações sociais e, portanto, que são alvos de conflito, de um lado as agências buscando perpetuar a manipulação social e de outro os indivíduos procurando reapropriar os recursos da sociedade. Assim, os novos movimentos sociais passam a se opor à intrusão do Estado e do mercado na vida social, reclamando o direito dos indivíduos definirem suas próprias identidades e determinarem suas vidas privadas. Não visam ganhos materiais, mas sim desafiam noções de política e sociedade e defendem a autonomia pessoal, sendo a defesa da identidade e da existência pessoal o que passa a servir de base nos novos conflitos, os indivíduos demandando coletivamente "o direito de realizarem sua própria identidade: a possibilidade de dispor de sua criatividade pessoal, sua vida afetiva e sua existência biológica e interpessoal"18 (MELUCCI, 1980, p. 218, tradução livre).

Como características inovadoras, Melucci afirma que nesses novos movimentos sociais há uma diversidade de fatores que os caracterizam: há o fim da separação entre as esferas pública e privada, já que áreas que eram da zona privada (relações sexuais, relações interpessoais e identidade biológica) tornam-se cenário de ações coletivas ${ }^{19}$; as ações não são mais orientadas para a conquista de poder político ou derrubada do Estado, sendo destinadas a luta por direitos humanos e ao controle de um campo de autonomia e de independência do sistema; a solidariedade é vista como um objetivo, uma vez que as lutas centram-se na questão da identidade coletiva; e a natureza antiautoritária e anti-hierárquica, as ações ocorrendo por meio da participação direta, com a consequente rejeição da representação, considerando que a representação é vista como forma de reprodução dos mecanismos de controle e manipulação contra os quais as lutas direcionam-se.

Vislumbra-se, pois, que na visão de Melucci, há estrita correlação entre aspectos sociais, culturais e políticos, bem como entre esses e a existência de condições e recursos favoráveis à mobilização, aspectos que influenciam a emergência e o desenvolvimento de movimentos sociais. A consolidação, pois, de uma sistemática internacional e regional de proteção de direitos humanos, cumulada com transformações políticas e culturais nos Estados pertencentes a tais sistemáticas, constituiriam, então, aspectos relevantes a influir no processo de elaboração de reivindicações sociais. É nesse sentido que se denota a correspondência entre a Sistemática Interamericana (que cria uma série de recursos favoráveis à mobilização) e o processo de formulação de demandas pelos atores domésticos na América Latina (aspecto a ser tratado no próximo tópico).

Assim, os movimentos sociais, entendidos como "ações sociopolíticas construídas por atores sociais coletivos, pertencentes a diferentes classes e camadas sociais, articuladas em certos cenários da conjuntura socioeconômica e política de um país, criando um campo político de força social na sociedade civil" (GOHN, 1997, p. 251), destacam-se por serem ações que, de acordo com as ideias de Melucci (1980) desenvolvem um processo social, político e cultural que cria uma identidade coletiva para o movimento, ante o interesse comum dos atores sociais. Em tal sentido, caracterizam-se por serem mobilizações destinadas a transformações, dentre as quais se destacam as lutas por melhorias no âmbito social e, em especial, para a adequada tutela de direitos humanos.

Os movimentos sociais, nessa perspectiva, passam a ser vistos como sintomas da nossa sociedade, todos eles causando impactos nas estruturas sociais, mesmo que em graus distintos e

\footnotetext{
${ }^{18}$ No original: "the right to realize their own identity: the possibility of disposing of their personal creativity, their personal creativity, their affective life, and their biological and interpersonal existence".

${ }^{19}$ Consoante pontua Melucci (1980), ante a extinção da distinção entre público e privado, as relações interpessoais se tornam zonas de conflito, deslocando os conflitos para questões como sexo, contracultura, gênero, relação com o meio ambiente, entre outros. Nas palavras do teórico: "os mecanismos de acumulação já não são alimentados pela simples exploração da força de trabalho, mas pela manipulação de complexos sistemas organizacionais, pelo controle da informação e dos processos e instituições formadores de símbolos, ao lado da interferência nas relações pessoais" (MELUCCI, 1980, p. 217-218).
}

Revista de Direito Brasileira | Florianópolis, SC | v. 27 | n. 10 | p.31-50 | Set./Dez. 2020 
mesmo que gerem resultados distintos. Representam a ação dos homens na história (GOHN, 1997), os conflitos sociais, os germes de resistência social e, quando bem sucedidos, as transformações sociais (CASTELLS, 1999) no processo de busca pela efetiva tutela de direitos humanos.

\section{NOVOS MOVIMENTOS SOCIAIS E AMÉRICA LATINA: A SOCIEDADE CIVIL SEU PAPEL NA EXIGIBILIDADE DE CONFORMAÇÃO DAS PRÁTICAS INTERNAS ÀS NORMAS INTERAMERICANAS}

Evidenciados os elementos característicos dos movimentos sociais em geral, passa-se à análise dos motivos que levam à irrupção de movimentos sociais na América Latina e de quais os seus efeitos, para o fim de constatar como que a mobilização social cria meios para a exigibilidade de conformação das normas e práticas internas às normas interamericanas de proteção dos direitos humanos e, ainda, para a criação de espaços destinados ao exercício ativo da cidadania, esta tida como essencial para a continuidade na proteção de direitos no âmbito doméstico.

O histórico dos novos movimentos sociais levados a efeito na América Latina a partir da década de 1970 encontra estrita ressonância com mudanças políticas e culturais ocorridas no período, que levaram ao processo de redemocratização dos países latino-americanos. Surgem eles, inicialmente, como movimentos de contraposição aos regimes ditatoriais instalados na maioria dos países da região a partir da década de 1960, período no que o próprio SIDH desenvolveu-se, este servindo como importante recurso para dar forma às lutas políticas para o fim do autoritarismo no período.

Os regimes repressivos anteriormente vigentes no espaço latino-americano instalaram na região uma ruptura política de retrocesso no que diz respeito à tutela de direitos humanos, bem como levaram ao surgimento de uma forma de autoritarismo social (este relativo à legitimação de distintas formas de discriminação e opressão social). As ditaduras, além de legitimarem práticas abusivas que violavam direitos básicos dos cidadãos, como o direito à vida, à liberdade e à integridade pessoal, limitaram os canais disponíveis à oposição e à expressão política e suprimiram ou restringiram as instituições políticas tradicionais. Em razão de tal retrocesso, os regimes autoritários também acabaram por limitar a mobilização popular, a liberdade de imprensa e qualquer forma de oposição política por um longo período de tempo (VIOLA; MAINWARING, 1987).

A progressiva liberalização dos sistemas políticos a partir do final da década de 1970, decorrentes sobretudo da crise do sistema repressivo e da crise econômica que assolava a região, cumulada com a progressiva consolidação da sistemática interamericana de proteção de direitos humanos, possibilitou a expressão de demandas sociais ${ }^{20}$, seja por meio de movimentos sociais ou por meio de mobilizações de rua de alcance nacional diretamente ligadas à mudança política e às exigências de democratização das instituições políticas, como o "Diretas Já" no Brasil e as diversas mobilizações de rua no Chile, Uruguai e Argentina (GOIRAND, 2009).

Isso porque a sociedade emerge no período como uma alternativa política ao Estado e à opressão. Surge, desse modo, uma variedade de manifestações cívicas públicas contra os poderes autoritários e as restrições a direitos civis e políticos, reivindicando a regulamentação ou a criação de direitos civis, políticos, sociais, culturais, étnicos, de gênero e ambientais.

Frisa-se, consoante o aludido anteriormente, que os movimentos sociais em geral são respostas diretas à mutabilidade das circunstâncias históricas e culturais. No caso dos novos movimentos sociais na América Latina, o que há de se compreender é que eles vieram como resposta à insegurança da população decorrente da impotência das instituições políticas clássicas,

\footnotetext{
${ }^{20}$ Nesse tocante, Goirand (2009) cita diversos fatores que levaram à intensificação das mobilizações sociais no período: a abertura de espaços na Igreja Católica para a oposição política, bem como o incentivo dado pelos padres à politização dos militantes; o início da liberação progressiva dos regimes autoritários; o esgotamento das ideologias e dos grupos revolucionários que defendiam a luta armada; a crise econômica da década de 1980.
} 
visando reorganizar a vida social e política e lutando eles "não apenas por melhores condições de vida, indispensáveis para a satisfação das necessidades humanas, mas contra as formas autoritárias de exercício do poder político estatal e contra as determinações econômicas e a mercantilização generalizada da vida social" (VIEIRA, 2013, p. 513-514).

Caracterizando-se pela existência de uma magnitude de desigualdades sociais, pela exploração econômica e pela dominação política, a concentração de riquezas e a exclusão social eram (e ainda são) evidentes no espaço político e social latino-americano, fato que contrasta diretamente com os direitos que o SIDH visa tutelar, de modo que tal discrepância avultou uma variedade de tensões coletivas, originadas das reivindicações que refletem carências materiais, necessidades e direitos básicos e resistência à opressão (WOLKMER, 2001). Nesse cenário, as lutas sociais surgidas no período destinaram-se a mudanças no sistema político vigente (rumo à democratização), à erradicação das patentes desigualdades sociais que caracterizavam as práticas culturais e sociais (ALVAREZ; DAGNINO; ESCOBAR, 1998) e a busca pela maior tutela de direitos humanos básicos.

Wolkmer (2001) sustenta que os novos movimentos sociais que rompem nos países ocidentais centrais (EUA e Europa) surgem em decorrência de uma série de fatores que não se aplicam ao contexto latino-americano, motivo pelo qual devem ser estudados separadamente.

Como frisado pelo teórico, nos países centrais, os movimentos decorrem de uma crise de racionalidade resultante uma ruptura cultural no período (esta decorrente da globalização, caracterizada pela individualização da sociedade e a desestabilização das relações humanas), do esgotamento do modelo de Estado (seja na versão intervencionista keynesiana ou na versão do populismo-desenvolvimentista) e da crise do modelo de desenvolvimento do bem-estar material (resultante da crise econômica, desemprego, poluição, escassez de recursos, ameaça nuclear, etc). Caracterizam-se pelo seu caráter policlassista e do fato de que advêm de fatores conjunturais não necessariamente econômicos, no contexto da racionalização do espaço e da vida urbana em crise.

Além disso, em grande parte dos países centrais, a sociedade já havia conquistado o reconhecimento e a garantia de uma grande variedade de direitos civis, políticos e sociais básicos, o que permitiu que os novos movimentos sociais destinassem-se à formulação de demandas que não estivessem eminentemente atreladas à busca por direitos básicos, mas sim que se referissem a necessidades de segurança e de consumo, como direitos difusos, direitos das minorias, direitos relativos à proteção ambiental e ao desarmamento, direitos à bioética, entre outros (WOLKMER, 2001).

Já nos países do capitalismo periférico, como na América Latina, os novos movimentos sociais, apesar de também serem pluriclassistas, refletiam na realidade lutas pela redistribuição dos meios de consumo coletivo e pela melhoria das condições de vida. Surgem eles das carências materiais e do aumento das demandas por direitos humanos, sendo eles colocados como resposta para uma nova organização da sociedade, que reivindicava a "ruptura com toda a herança política eminentemente calcada em um espectro elitista, antipopular, autoritário e corporativista" (WOLKMER, 2001, p. 126). Desenvolvem-se pela necessidade de mudanças conjunturais, exigindo melhorias nas condições de vida, e de mudanças estruturais, ante a dominação autoritária do Estado.

Dessa maneira, nas sociedades latino-americana as reivindicações destinam-se sobretudo ao reconhecimento de direitos civis, políticos e sociais básicos, seja no sentido de tornar efetivos direitos formalmente reconhecidos, seja no sentido de exigir a edição de "novos" direitos ainda não reconhecidos pela legislação positiva estatal, ainda que já reconhecidos nos âmbitos regional e internacional de tutela de direitos.

No cenário latino-americano tem-se, portanto, uma variedade de movimentos relacionados à oposição à autoridade estatal repressiva e à busca pela concretização de direitos básicos, dentre os quais se destacam: o Movimento dos Sem Terra, no Brasil, reivindicando a reforma agrária; o Movimento ecologista, no Equador, o qual se opunha às grandes empresas 
exploradoras de petróleo; o Movimento Urbano Popular, no México, em prol da habitação; as organizações piquiteras na argentina; as mobilizações indigenistas no Equador e na Bolívia; o Movimento Nacional dos Catadores de Materiais Recicláveis, no Brasil; o Movimento das "Mães da Praça de Maio", na Argentina; movimentos relacionados à libertação nacional, com a atuação de pastorais da Igreja; e o Movimento Sendero Luminoso, no Peru, entre outros ${ }^{21}$.

Desta feita, a diversidade de cenários políticos e sociais geram movimentos diferentes. Enquanto no cenário latino-americano os novos atores sociais buscavam conquistar novos direitos a partir da expansão da democracia e por meio do enfrentamento ao poder dos regimes autoritários instalados na região, buscando novas formas de sociabilidade e novos direitos (relativos a liberdades civis básicas e a igualdade socioeconômica) que não fossem reprimidas pelo Estado, na Europa e nos EUA os novos movimentos eram basicamente destinados a expandir e tornar efetivos um conjunto de direitos basicamente aceitos e institucionalizados, reivindicando o direito a novos estilos de vida, novas formas de relacionamento humano e preservação ecológica (VIOLA; MAINWARING, 1987).

No tocante ao caráter "novo" desses movimentos sociais latino-americanos, Wolkmer (2001) bem ressalta que esses movimentos referem-se a ações conscientes postas em movimento relativas a movimentos rurais e urbanos (sem-terra) e a movimentos de mulheres, negros, direitos humanos, ecólogos, pacifistas e religiosos que visavam romper com a sociedade dominante e sugerir como alternativa práticas democráticas mais participativas. Nas palavras do teórico:

O "novo" está no fato de se tratar de manifestações com capacidade de surgir "fora" da cena política institucional, fundadas em razões que não só transcendem os estreitos interesses da produção e consumo, mas, sobretudo, compõem nova identidade coletiva, capaz de romper com a lógica do paradigma social dominante e se libertar das formas opressoras de manipulação e cooptação, criando alternativas implementadoras de práticas democráticas participativas (WOLKMER, 2001, p. 138).

$\mathrm{Na}$ medida em que os arranjos institucionais e as regras formais de legitimidade deixam de ser vistos como apropriadas e suficientes para processar a diversidade de demandas da sociedade (fatores que implicam a crise na representação política), os movimentos sociais instauram-se para o estabelecimento de uma política pluralista não institucional e autossustentável, para a afirmação de identidades coletivas e para a promoção de espaços democráticos, descentralizados e participativos, em que o foco se refere à preservação de condições mínimas de dignidade humana (WOLKMER, 2001).

Com relação às características dos movimentos sociais na região, Pontes (2015) pontua algumas: a diversidade de movimentos existentes, com distintas formas de organização; a hegemonia de movimentos populares (lutas por terra, habitação, direito à alimentação e outras necessidades e direitos sociais básicos, sendo formas de resistência à exclusão social) em face de outros tipos de movimentos (que visam a participação, direitos, a cidadania e que se baseiam na

\footnotetext{
${ }^{21}$ Kärnen (1987, p. 26) destaca uma série de movimentos surgidos no período e que se estenderam após a afirmação da democracia formal na região. Conforme ressalvado, exemplos marcantes seriam o "movimento operário democrático e popular surgido no Brasil, liderado por Luís Ignácio da Silva (Lula), e que logo derivou o Partido dos Trabalhadores; o Sandinismo, que surgiu na Nicarágua como um grande movimento social, de caráter pluriclassista e pluriideológico; as formas diferentes que assumem a luta popular no Peru, tanto ao nível dos bairros ("Pueblos Jóvenes") como ao nível regional (Frentes Regionais para a Defesa dos Interesses do Povo); as novas experiências de "greves cívicas nacionais", com a participação de sindicatos, partidos políticos e organizações populares (grupos eclesiásticos de base, comitês de mulheres, grupos estudantis, culturais, etc.) no Equador, na Colômbia e no Peru; os movimentos de ocupações ilegais de terrenos em São Paulo; as invasões maciças de terras pelos camponeses do México e outros países, as tentativas de autogestão nas favelas das grandes cidades como Caracas, Lima e São Paulo; os comitês de defesa dos Direitos Humanos e as Associações de Familiares de Presos e Desaparecidos, sendo estas últimas iniciativas surgidas basicamente dos movimentos sociais"
}

Revista de Direito Brasileira | Florianópolis, SC | v. 27 | n. 10 | p.31-50 | Set./Dez. 2020 
identidade coletiva); o grande papel da religião, com os movimentos incentivados pela Igreja Católica possuindo grande repercussão; o foco na questão indígena e a luta pela preservação de suas tradições culturais; a resistência ao autoritarismo nos movimentos populares e a luta pela inclusão nos novos movimentos sociais; a vertente marxista gramsciana dos movimentos populares; o foco na questão agrária; a presença tanto de estratégias violentas quanto não violentas; entre outras.

No Brasil, mais especificamente, os movimentos que se desenvolveram a partir do fim da década de 1970 eram caracterizados pela busca da autonomia de grupos populacionais, os quais se opunham ao Estado autoritário e a hegemonia das elites. Tinham os movimentos, então, caráter de antagonismo e oposição, predominando aqueles de cunho popular, que demandavam recursos necessários à sobrevivência cotidiana e de cunho eminentemente político como o "Diretas Já" (PONTES, 2015).

Essas lutas por direitos e por uma sociedade mais justa e igualitária na década de 1980 levaram a importantes vitórias que implicaram a construção de espaços púbicos de representação, bem como levaram à redemocratização dos países latino-americanos e à edição de Constituições democráticas na região. Diante disso, os países latino-americanos em geral entraram nos anos 90 formalmente com democracias consolidadas, que reconhecem direitos sociais, garantias civis e prerrogativas dos cidadãos.

Contudo, apesar do reconhecimento formal, a população latino-americana continuou a conviver diariamente com violência, violações de direitos humanos, poder arbitrário e discriminação de classes, de gênero, étnicas e sexuais, fato que, para Paoli e Telles (1998), evidencia que os Estados não possuem a capacidade ou vontade política de impor o cumprimento de direitos humanos e implica a necessidade de constantes lutas para exigir que estes sejam respeitados na região.

Em que pese tal cenário, certo é que as lutas dos anos 80 foram importantes para a construção de um legado, este relativo ao fato de que se conseguiu produzir no cenário político latino-americano, após décadas de poder arbitrário e repressão, um espaço púbico informal, descontínuo e pluralístico em que as demandas por direitos possuem a possibilidade de circular, até mesmo ante a elevação da consciência dos atores sociais quanto ao seu direito de ter direitos. Em razão disso, a sociedade civil se tornou mais receptiva ao reconhecimento de demandas populares (PAOLI; TELLES, 1998).

Ante tais mudanças na conjuntura política a partir da década de 1990 e a perpetuidade de variadas violações de direitos humanos, as lutas sociais persistiram. No entanto, o contexto das mobilizações foi novamente redefinido, afastando-se em certa medida das reivindicações por cessação dos regimes autoritários (até mesmo ante a ruptura formal com os regimes ditatoriais), e aproximando-se de questões relacionadas à afirmação de identidades culturais.

A característica imperante desses novos movimentos sociais é justamente a ênfase em valores como a identidade, o reconhecimento social, o respeito ao indivíduo, os direitos humanos, as condições de vida e na reivindicação da participação na tomada de decisões no cenário político (INGLEHART, 1971).

Nesse cenário, trabalhadores, mulheres, negros, minorias e classes sociais marginalizadas se tornam e se reconhecem como sujeitos de direitos, que possuem a potencialidade de tornar públicas questões de injustiça na formulação de suas reivindicações e demandas. Esses atores, ante a redefinição da noção de direitos e de cidadania e diante da busca pelo aumento dos mecanismos de repressão, passam a ter a capacidade de desestabilizar e subverter hierarquias simbólicas que previamente os colocavam em uma posição de discriminação e exclusão (PAOLI; TELLES, 1998).

Os movimentos latino-americanos, dessarte, passaram a representar um paradigma alternativo de cultura política, pelos quais não mais se reivindica a destruição do poder estabelecido 
(Estado), mas sim pequenas transformações cotidianas (WOLKMER, 2001) ${ }^{22}$.

A busca pela satisfação de necessidades humanas fundamentais passa a não se limitar meramente às necessidades sociais ou materiais, mas também a compreender necessidades existenciais (de vida) e culturais. Passa a haver uma heterogeneidade mais evidente de movimentos nos países latino americanos, os quais, para Wolkmer (2001), buscam em sua essência o direito de satisfazer necessidades existenciais (direito à alimentação, saúde, segurança, água, vida), materiais (direito à terra, à habitação, ao trabalho, ao salário, ao transporte, à creche), sócio-políticas (direito à cidadania e de participação, reunião e associação), culturais (direito à educação, liberdade de crença e religião, diferença, lazer) e difusas (direito à preservação ecológica, proteção ao consumo) e o direito das minorias e diferenças étnicas (direito das mulheres, do negro, do índio, da criança e do idoso) $)^{23}$.

Surgem, portanto, movimentos sociais mais centrados em questões étnicas ou de revalorização da vida humana, como os movimentos das mulheres, ecológicos, de negros e indígenas (os quais tinham eminente caráter culturalista, que se tornam representações simbólicas para a reconstrução da cidadania), surgindo sobretudo como reação à violência generalizada, à corrupção, ao clientelismo, ao corporativismo e aos escândalos da vida política característicos do período, que levaram a reações no plano moral ${ }^{24}$. Além disso, mobilizações estritamente em torno da defesa de direitos humanos básicos se fortalecem, destacando-se, como exemplo, as mobilizações na Colômbia pela paz civil, as mobilizações reivindicando a reabertura de processos contra os responsáveis pelos regimes militares no Chile, e a ampliação das mobilizações indigenistas, sobretudo no Equador e na Bolívia (GOIRAND, 2009).

É diante de tal perspectiva que se vislumbra que os movimentos sociais no espaço latinoamericano na realidade se referem atualmente à própria luta pela tutela internacional de direitos humanos. A partir do retorno à democracia na América Latina, o SIDH eleva sua influência na região, sua atenção voltando ao desafio de melhorar a qualidade do governo democrático e enfrentar os desafios de direitos humanos em um contexto regional em que apesar de a democracia eleitoral ter tido avanços, as violações de direitos humanos continuam a ser propagadas.

As mobilizações possibilitam a consolidação de uma consciência crítica para a transformação das esferas domésticas e para garantir o resguardo aos direitos básicos de todos os cidadãos (VIEIRA, 2013). A retomada da dimensão humana, crítica e emancipatória da política como um lugar de convivência plural entre cidadãos foi, outrossim, possibilitada pelos movimentos sociais surgidos no fim do século passado, diante da procura dos indivíduos pelo reconhecimento de suas vozes, reivindicações e direitos.

Nesse contexto, os atores e movimentos sociais, consoante Jelin (1998) detiveram e detêm um duplo papel: por um lado, referem-se a lutas coletivas de reconhecimento recíproco destinados à garantia de direitos humanos, expressando identidades coletivas antigas e novas, com importantes componentes culturais e simbólicos; por outro, referem-se a intermediários políticos apartidários,

\footnotetext{
${ }^{22}$ Pontes (2015, p. 116) destaca que a novidade dos movimentos sociais a partir da década de 1990 ocorreu em dois pontos principais. Primeiro, houve o deslocamento das reivindicações populares, ligadas a questões de infraestrutura básica e ao consumo coletivo (transporte, saúde, educação e moradia), para questões sociais ligadas ao direito à vida e à sobrevivência dos indivíduos e para demandas por terra. Segundo, houve o ressurgimento de questões ligadas à moral, as quais ganharam lugar central nas lutas sociais, já que a ausência de ética na política e a agressão a certos valores da sociedade em relação à gestão da coisa pública levaram a reações dessa sociedade, eclodindo movimentos sociais de "base pluriclassista, liderados pelas camadas médias e articulados em torno de problemáticas de gênero, raça e idade, dando lugar a lutas cívicas e verdadeiras cruzadas nacionais".

${ }^{23}$ Viola e Mainwaring (1987) salientam que apesar da heterogeneidade dos novos movimentos, todos compartilham de alguns valores importantes, conferem grande ênfase às práticas democráticas e participativas, rejeitam relações elitistas e hierarquizadas, valorizam a solidariedade e favorecem a cooperação em lugar da competição.

${ }^{24}$ Destacam-se como movimentos importantes surgidos no período o Movimento Zapatista de Libertação Nacional do México; o Movimento ao Socialismo dos povos indígenas da Bolívia; o Grito dos Excluídos em distintos Estados; o Movimento Cadeira Vazia, no Equador; o movimento emancipatório da mulher; os movimentos ambientalistas; os movimentos pacifistas; o movimento negro, entre outros (PETRY, 2008).
}

Revista de Direito Brasileira | Florianópolis, SC | v. 27 | n. 10 | p.31-50 | Set./Dez. 2020 
que trazem as necessidades e demandas d/e vozes desarticuladas para a esfera pública, vinculandoas às instituições estatais.

Os novos movimentos passaram a politizar a vida quotidiana e as relações sociais, transformando elas em objetos legítimos de demanda. Como aponta Goirand (2009), os movimentos, ao girarem em torno de questões relacionadas ao meio ambiente, ao gênero, às relações sexuais ou à moralidade, acabaram por remeter a questões eminentemente políticas, ante a reivindicação indireta do reconhecimento de direitos humanos básicos, como a liberdade de expressão e associação e a eliminação das discriminações existentes.

Por meio dos movimentos opera-se uma dialética em que a sociedade civil não se torna apenas um ator social, mas um ator político ativamente engajado na defesa de direitos humanos, fato que para as camadas subalternas na América Latina é um acontecimento extremamente relevante em termos sociais e culturais (SCHERER-WARREN, 2008). Ademais, conforme preconiza a mesma teórica, em estudo diverso, é a formação de uma nova cultura política de base que se constitui como valor fundamental desses novos movimentos sociais (SCHERERWARREN, 1987).

O que se percebe da análise dos novos movimentos sociais no cenário latino americano (tanto aqueles surgidos no final da década de 1970, quanto aqueles que melhor se desenvolveram a partir da década de 1990) é que eles detêm como foco a garantia de respeito, no âmbito nacional, dos direitos humanos consagrados no cenário internacional, bem como possuem como objetivo primordial a consagração da democracia, de cunho mais participativo, no cenário latino-americano, justamente para que a sociedade possua condições de ativamente participar do processo político e exigir a efetiva tutela de direitos por ela considerados relevantes. Como ressalta Vieira (2013, p. 488):

As práticas criativas e lutas sociais contemporâneas desenvolvidas por diversificados movimentos sociais podem ser consideradas como a explicitação de um processo histórico pela busca do reconhecimento e realização da democracia e dos direitos humanos no cenário nacional e global, abrangendo as diversas dimensões da liberdade, igualdade e solidariedade, expressas como direitos individuais, sociais e democráticos. Hoje aparecem ao lado das lutas para a efetivação dos direitos humanos básicos, como o direito à vida, o reconhecimento das liberdades individuais de todos e pela garantia das condições para a concretização da igualdade social e dignidade humana, com a implantação do Estado Democrático de Direito, agregam-se novas lutas pelo reconhecimento e concretização de novos direitos, como o de autodeterminação dos povos e o respeito às diferenças culturais e grupais através de uma convivência plural, democrática e solidária.

Desta feita, o que fundamentalmente encontra-se em disputa na América Latina, desse modo, é a luta por direitos humanos e a luta pela reconfiguração da democracia no cenário latinoamericano, ante a noção que apenas por meio da definição dos participantes, instituições, processos, agenda e escopo que fazem parte da arena política pela sociedade civil cria-se o cenário necessário para o contínuo desenvolvimento de reivindicações na região (ALVAREZ; DAGNINO; ESCOBAR, 1998). As lutas pela percepção das carências sociais como direitos e pelo reconhecimento da igualdade e do direito à diferença implicam a redefinição da noção de cidadania, já que levam à redefinição dos atores sociais como cidadãos iguais, além de demonstrarem o papel afirmativo dos movimentos sociais (DAGNINO, 1998).

Essa nova cidadania buscada pelos movimentos sociais redimensiona a noção do direito e do direito a ter direitos, bem como requer uma nova sociabilidade e a constituição de uma participação ativa dos cidadãos no processo de definição da política e dos membros dessa (DAGNINO, 1998). O exercício da cidadania, com a participação ativa da sociedade civil, acaba 
por permitir que o Estado reconheça as reivindicações políticas e jurídicas dos cidadãos e institucionalize as soluções aos problemas levantados pelos cidadãos (VIEIRA, 2013).

Como muito bem aduzem Alvarez, Dagnino e Escobar (1998), em razão de as classes subalternas terem sido historicamente relegadas ao status de não cidadãos na América Latina, a multiplicação de arenas públicas (característica do processo de expansão e consolidação da democracia na região) permite que a exclusão sociocultural, de gênero, racial, sexual e econômica possam ser contestadas e ressignificadas por meio de reivindicações e lutas sociais. Nesse sentido pontua Jelin (1998, p. 413, tradução livre), ao pontuar que:

O papel expressivo na construção de identidades coletivas e do reconhecimento social, e o papel instrumental que desafia os arranjos institucionais existentes, são essenciais para a vitalidade da democracia. [...] movimentos sociais e organizações não-partidárias devem ser vistos como uma maneira de garantir uma democracia dinâmica - que inclui um dispositivo de autocontenção para a expansão de suas próprias fronteiras ${ }^{25}$.

Ante a afirmação do direito do sujeito latino-americano a ter direitos, do reconhecimento desse sujeito como ator social e político, autônomo e independente e da construção de espaços públicos destinados à participação ativa de classes marginalizadas no processo político, os movimentos contribuíram, desta feita, para a invenção de uma nova sociedade, de uma nova concepção de cidadania e, consequentemente, para avanços na proteção de direitos humanos, como produto da democratização da gestão estatal (DAGNINO, 1998).

Não se pode perder de vista que apesar de as democracias que se firmaram na América Latina continuarem a perpetuar desigualdades sociais e econômicas, houve uma progressiva perda da visibilidade de muitos movimentos sociais. Contudo, tal fato não descaracteriza a constatação de que os movimentos sociais são elementos importantes para a configuração dos processos democráticos no país e para a efetivação dos direitos humanos protegidos no âmbito global e no SIDH, porém não garantidos em sua totalidade no cenário internacional.

Nesse sentido, os atores sociais aparecem como agentes produtores de história que buscam a democratização da cultura e da vida coletiva, colocando-se como interlocutores de uma esfera pública defensora da democracia e dos direitos da humanidade. Nessa medida, são atores importantes para o processo de exigência de conformidade das práticas internas às diretrizes internacionais e regionais, no que diz respeito à proteção de direitos humanos.

\section{CONCLUSÃO}

Em que pese sejam os Estados latino-americanos formalmente reconhecidos como democracias, a América Latina desde o processo de redemocratização até os dias atuais continua sendo caracterizada pela elevada desigualdade social e pela perpetuidade de grandes mazelas que afetam a população como um todo. Diante de tal cenário, a região é marcada pela presença de uma série de conflitos, sendo palco de movimentos sociais que buscam, em suma (seja por meio de reivindicações de cunho identitário, ou de demandas relacionadas a necessidades sociais básicas e de lutas por ampla participação democrática), a concretização de direitos humanos básicos a todos os nacionais latino-americanos, conforme a proteção regional oferecida no SIDH.

Não obstante seja inerentemente um processo de responsabilidade das autoridades estatais, a adequação das práticas e normas internas às normas interamericanas de proteção de direitos humanos decorre necessariamente da mobilização da sociedade civil, a qual, por meio de

\footnotetext{
${ }^{25}$ No original: "The expressive role in the construction and collective identities and social recognition, and the instrumental role that challenges the existing institutional arrangements, are both essential for the vitality of democracy. [...] social movements and nonpartisan organizations should be seen as a way to ensure a dynamic democracy - one that includes a self-contained device for expanding its own frontiers".
}

Revista de Direito Brasileira | Florianópolis, SC | v. 27 | n. 10 | p.31-50 | Set./Dez. 2020 
movimentos sociais, continuamente demanda dos Estados que estes ajam de acordo com os compromissos por eles assumidos na esfera internacional. A partir da elaboração de demandas e reivindicações tendentes a fazer valer os direitos protegidos pela sistemática interamericana de proteção de direitos humanos, os movimentos sociais constituem-se, dessa forma, como elementos imprescindíveis para transformações sociais destinadas à proteção de necessidades básicas dos cidadãos latino-americanos.

Neste sentido, a mobilização social não deve ser vista como espécie de anomia social, justamente por ser ela que garante a progressiva tutela dos direitos humanos no âmbito doméstico e, ao mesmo tempo, possibilita a construção de espaços públicos destinados a contínuas reivindicações de caráter cultural, social e político. Como forma de resistência e defesa de direitos humanos, os novos movimentos sociais, os quais possuem cunho cultural, identitário e progressista, refletem as necessidades regionais de mudanças conjunturais, de melhoria nas condições de vida da população e de contínuo reconhecimento de direitos civis, políticos e sociais básicos aos cidadãos da região.

O reconhecimento formal de direitos humanos no cenário regional não necessariamente leva a mudanças internas na proteção de direitos humanos, sobretudo quando se trata da América Latina, região na qual a população continua a conviver diariamente com cenários de violência, de discriminação e de violação de direitos humanos. Tal fato evidencia a incapacidade das autoridades estatais protegerem necessidades básicas da população, exigindo da sociedade civil o constante empreendimento de lutas sociais tendentes a concretizar os direitos protegidos pelo SIDH. As mobilizações possibilitam, assim, transformações importantes na tutela de direitos no âmbito interno, criando condições para o resguardo de direitos básicos a todos os cidadãos.

\section{REFERÊNCIAS}

ALEXANDER, Jeffrey C. Ação coletiva, cultura e sociedade civil: secularização, atualização, inversão, revisão e deslocamento do modelo clássico dos movimentos sociais. Revista Brasileira de Movimentos Sociais, v. 13, n. 37, p. 5-31, 1998.

ALONSO, Angela. As teorias dos movimentos sociais: um balanço do debate. Lua Nova, v. 76, p. 49-86, 2009.

ALVAREZ, Sonia E.; DAGNINO, Evelina; ESCOBAR, Arturo. Introduction: the cultural and the political in Latin American social movements. In: ALVAREZ, Sonia E.; DAGNINO, Evelina; ESCOBAR, Arturo (Eds.). Cultures of politics, politics of cultures: re-visioning Latin American social movements. Colorado-USA: Westview Press, 1998, p. 1- 32.

CARVALHO, Luciani Coimbra de; CALIXTO, Angela Jank. Diálogos interjudiciais: a obrigatoriedade de seu desenvolvimento no Sistema Interamericano de Proteção dos Direitos Humanos. Revista eletrônica do curso de direito da UFSM, v. 14, 2019.

CASTELLS, Manuel. O poder da identidade. Tradução de Klauss Brandini Gerhardt. São Paulo: Paz e Terra, 1999, v. 2.

DAGNINO, Evelina. The cultural politics of citizenship, democracy, and the state. In: ALVAREZ, Sonia E.; DAGNINO, Evelina; ESCOBAR, Arturo (Eds.). Cultures of politics, politics of cultures: re-visioning Latin American social movements. Colorado-USA: Westview Press, 1998, p. 33- 63.

DELLA PORTA, Donatella; DIANI, Mario. Social movements: an introduction. $2^{\text {th }}$ ed. Malden: Blackwell Publishing, 2006. 
GOHN, Maria da Glória. Teorias dos movimentos sociais: paradigmas clássicos e contemporâneos. São Paulo: Edições Loyola, 1997.

GOIRAND, Camille. Movimentos sociais na América Latina: elementos para uma abordagem comparada. Estudos Históricos, Rio de Janeiro, v. 22, n. 44, 2009, p. 323-354.

HABERMAS, Jürgen. New social movements. Telos, New York, n. 49, p. 33-37, 1981.

INGLEHART, R. The silent revolution in post-industrial societies. American Political Science Review, n. 65, 1971.

JELIN, Elizabeth. Toward a culture of participation and citizenship: challendes for a more equitable world. In: ALVAREZ, Sonia E.; DAGNINO, Evelina; ESCOBAR, Arturo (Eds.). Cultures of politics, politics of cultures: re-visioning Latin American social movements. Colorado-USA: Westview Press, 1998, p. 405- 414.

KÄRNEN, Hartmut. Movimentos sociais: revolução no cotidiano. In: SCHERER-WARREN, Ilse; KRISCHKE, Paulo J. (Orgs.) Uma revolução no cotidiano? Os novos movimentos sociais na América do Sul. São Paulo: Editora Brasiliense, 1987, p. 19-34.

MCADAM, Doug. Political Process and the Development of Black Insurgency: 1930-1970. Chicago: University of Chicago Press, 1982.

MCADAM, Doug; TARROW, Sidney; TILLY, Charles. Dynamics of contention. Cambridge: Cambridge University Press, 2001.

MCCANN, Michael. Law and social movements: contemporary perspectives. Annual Review of Social Sciences, v. 2, p. 17-38, 2006.

MCCARTHY, John D; ZALD, Mayer N. Resource mobilization and social movements: a partial theory. The American Journal of Sociology, v. 82, n. 6, 1977, p. 1212-1214.

MELUCCI, Alberto. The new social movements: a theoretical approach. Social Science Information, v. 19, no 2, 1980, p. 199-226.

ORGANIZAÇÃO DOS ESTADOS AMERICANOS. Convenção Americana de Direitos Humanos. 22 de novembro de 1969. Disponível em:

<https://www.cidh.oas.org/basicos/portugues/c.convencao_americana.htm>. Acesso em: 26 jan. 2020.

PAOLI, Maria Celia; TELLES, Vera da Silva. Social rights: conflicts and negotiations in contemporary Brazil. In: ALVAREZ, Sonia E.; DAGNINO, Evelina; ESCOBAR, Arturo (Eds.). Cultures of politics, politics of cultures: re-visioning Latin American social movements. Colorado-USA: Westview Press, 1998, p. 64- 92.

PETRY, Almiro. A democracia e os direitos humanos na América Latina. Porto Alegre, Universidade Vale do Rio dos Sinos, 2008. Disponível em:

<http://www.projeto.unisinos.br/humanismo/al/dem_dirhum.pdf>. Acesso em: 04/09/2019.

POLLETTA, Francesca; JASPER, James M. Collective identity and social movements. Annual Review of Sociology, v. 2, p. 283-305, 2001. 
PONTES, Beatriz Maria Soares. Movimentos sociais na América Latina: da teoria à realidade. Revista Movimentos Sociais e Dinâmicas Espaciais, Recife, v. 4, n. 1, p. 86-128, 2015.

SCHERER-WARREN, Ilse. Redes de Movimentos sociais na América Latina: caminhos para uma política emancipatória? Caderno CRH, Salvador, v. 21, n. 54, 2008, p. 505-517.

SCHERER-WARREN, Ilse. O caráter dos novos movimentos sociais. In: SCHERER-WARREN, Ilse; KRISCHKE, Paulo J. (Orgs.) Uma revolução no cotidiano? Os novos movimentos sociais na América do Sul. São Paulo: Editora Brasiliense, 1987, p. 35-53.

SIMMONS, Beth. Mobilizing for Human Rights: international law in domestic politics. Cambridge: Cambridge University Press, 2009.

TARROW, Sidney G. Power in movement: social movements and contentious politics. $3^{\text {rd }}$ ed. New York: Cambridge University Press, 2011.

TILLY, Charles. Movimentos sociais como política. Revista Brasileira de Ciência Política, n. 3, Brasília, 2010, p. 133-160.

TILLY, Charles. From mobilization to revolution. New York: Random House, 1978.

TOURAINE, Alain. Na fronteira dos movimentos sociais. Sociedade e Estado, Brasília, v. 21, n. 1, 2006, p. 17-28.

TOURAINE, Alain. The voice and the eye: an analysis of social movements. Cambridge: Cambridge University Press, 1981.

VIEIRA, Suzana Maria Gauer. Globalização, democracia e direitos humanos: os movimentos sociais e o processo de construção de uma esfera pública plural e democrática mundial. 2013. Tese (Doutorado em Direito) - Universidade do Vale do Rio dos Sinos (UNISINOS), São Leopoldo, 2013.

VIOLA, Eduardo; MAINWARING, Scott. Novos movimentos sociais: cultura política e democracia: Brasil e Argentina. In: SCHERER-WARREN, Ilse; KRISCHKE, Paulo J. (Orgs.) Uma revolução no cotidiano? Os novos movimentos sociais na América do Sul. São Paulo: Editora Brasiliense, 1987, p. 102-189.

WOLKMER, Antonio Carlos. Pluralismo jurídico: fundamentos de uma nova cultura no Direito. $3^{\mathrm{a}}$ ed. São Paulo: Editora Alfa Omega, 2001. 